\title{
Electrolyte-free milk protein solution influences sodium and fluid retention in rats
}

\author{
Kengo Ishihara ${ }^{1}$, Yoshiho Kato ${ }^{1}$, Ayako Usami ${ }^{1}$, Mari Yamada ${ }^{1}$, Asuka Yamamura ${ }^{1}$, Tohru Fushiki ${ }^{2}$ and \\ Yousuke Seyama ${ }^{1}$ \\ ${ }^{1}$ Laboratory of Biochemistry, Department of Human Nutrition, School of Life Studies, Sugiyama Jogakuen University, Hoshigaoka Motomachi 17-3, \\ Chikusa-ku, Aichi 464-8662, Japan \\ ${ }^{2}$ Laboratory of Nutritional Chemistry, Division of Food Science and Biotechnology, Graduate School of Agriculture, Kyoto University, Sakyo-ku, \\ Kyoto 606-8502, Japan
}

(Received 10 July 2012 - Final revision received 17 October 2012 - Accepted 17 October 2012)

Journal of Nutritional Science (2013), vol. 2, e8, page 1 of 7

doi:10.1017/jns.2012.24

Abstract

Milk is an effective post-exercise rehydration drink that maintains the net positive fluid balance. However, it is unclear which components are responsible for this effect. We assessed the effect of milk protein solution (MPS) obtained by dialysis on body fluid retention. Milk, MPS, milk electrolyte solution (MES), sports drink and water were administered to male Wistar rats at a dose of $6 \mathrm{ml} /$ rat after treadmill exercise. Total body fluid retention was assessed by urine volume $4 \mathrm{~h}$ after administration of hydrating liquids. The rate of gastric emptying was evaluated by a tracer method using ${ }^{13} \mathrm{C}$-labelled acetate. Plasma osmolality, $\mathrm{Na}$ and $\mathrm{K}$ levels, and urinary $\mathrm{Na}$ and $\mathrm{K}$ were measured by HPLC and osmometry, respectively. The gastric emptying rate was not delayed by MPS. During $4 \mathrm{~h}$ of rehydration, cumulative urine volumes differed significantly between treatment groups $(P<0 \cdot 05)$ with $4.9,2 \cdot 2$ and $3 \cdot 4$ $\mathrm{ml}$ from water-, milk- and MPS-fed rats, respectively. Thus, MPS elicited $50 \%$ of the total body fluid retention of milk. Plasma aldosterone levels were significantly higher in MPS- and milk-fed rats compared with water-fed rats. Plasma osmolality was maintained at higher levels in MPS-fed rats than in water- and MES-fed rats $(P<0 \cdot 05)$. Cumulative urine Na excretion was also suppressed in the milk- and MPS-fed groups compared with the MES-fed group. Our results demonstrate that MPS obtained by dialysis clearly affects net body water balance without affecting gastric emptying after exercise. This effect was attributed to retention of $\mathrm{Na}$ and water, and maintenance of plasma osmolality.

Key words: Rehydration: Water balance: Exercise: Milk: Sports drinks

As many individuals finish exercise in a hypohydrated state ${ }^{(1)}$, rehydration drinks are designed to restore water balance in a rapid and effective way after exercise. Traditional sports drinks containing isotonic electrolytes and carbohydrates provide benefits for voluntary fluid intake, rapid fluid absorption, improved performance and enhanced rehydration ${ }^{(2)}$. Commercial sports drinks are isotonic drinks typically containing 5-9\% (w/v) carbohydrate and small amounts of minerals in order to balance several benefits described earlier ${ }^{(3)}$.
Post-exercise rehydration fluids have to replace the water and electrolytes lost in the sweat secreted during exercise. As obligatory urine losses occur even in the dehydrated state, it is reported that the volume of water lost in urine after consuming sports drinks is greater than the volume of water consumed after exercise ${ }^{(4)}$. However, drinking plenty of plain water is undesirable, as it will inhibit thirst and will also promote a diuretic response. Maughan et al. ${ }^{(5)}$ suggested that postexercise rehydration drinks should contain moderately high

Abbreviations: MES, milk electrolyte solution; MPS, milk protein solution.

*Corresponding author: Kengo Ishihara, fax +8152782 7265, email kengo@sugiyama-u.ac.jp

(C) The Author(s) 2013. The online version of this article is published within an Open Access environment subject to the conditions of the Creative Commons Attribution-NonCommercial-ShareAlike licence <http://creativecommons.org/licenses/by-nc-sa/2.5/>. The written permission of 
levels of $\mathrm{Na}(50-60 \mathrm{mmol} / \mathrm{l})$ and some $\mathrm{K}$ to replace losses in the sweat. This suggestion is based on the total body fluid balance for some hours after fluid ingestion. In a human study, when subjects consumed a plain water volume equivalent to $150 \%$ of their sweat loss, their urine output showed a marked increase for 1 and $2 \mathrm{~h}$ after consuming water. This increasing of urine production led subjects to a euhydrated status only $1 \mathrm{~h}$ after consuming water.

Body fluid retention was directly related to the $\mathrm{Na}$ concentration of post-exercise rehydration drinks. Maughan \& Leiper $^{(6)}$ demonstrated that the body fluid balance was not negative in subjects who had ingested drinks of $52 \mathrm{mmol} / 1$ $\mathrm{Na}$ content but was negative in subjects who had ingested drinks of 2, 26 and $100 \mathrm{mmol} / 1 \mathrm{Na}$ content. The Na concentration of $52 \mathrm{mmol} / \mathrm{l}$ is two-fold higher than that in commercial sports drinks. Apart from the case when a large amount of $\mathrm{Na}$ was lost from sweating, some people have to pay special attention to $\mathrm{Na}$ intake to prevent high blood pressure ${ }^{(7)}$. To prevent excessive intake of $\mathrm{Na}$ from rehydration drinks, it is required to investigate the effect of various food components on body fluid retention and it is desirable that combining $\mathrm{Na}$ and these food components exerts independent additive effects on body fluid retention. There is some evidence demonstrating that the addition of $\mathrm{K}$ to a rehydration solution might increase fluid retention ${ }^{(4,8)}$, although other investigations have shown no effect of the addition of $\mathrm{K}$ to a rehydration solution $^{(9)}$. The addition of carbohydrate also exerts a mild influence on body fluid retention with increased carbohydrate concentration $^{(10)}$.

The addition of protein to a rehydration drink might increase fluid retention. It was demonstrated that low-fat milk containing approximately $36 \mathrm{~g} / 1$ protein is retained better than either a carbohydrate-electrolyte sports drink or water, and leads to a positive net fluid balance $3 \mathrm{~h}$ after drinking. Therefore, milk is a potential candidate for effective postexercise rehydration, probably due to its naturally high electrolyte content and a similar carbohydrate concentration to many commercially available sports drinks ${ }^{(11,12)}$. However, there existed a large number of compositional differences, other than protein content, between the low-fat milk and the carbohydrate-electrolyte sports drinks used (e.g. energy density, fat content, carbohydrate content, $\mathrm{Na}$ and $\mathrm{K}$ concentration and carbohydrate type), which makes the specific effects of the protein in the milk difficult to elucidate. James et al. ${ }^{(13)}$ demonstrated that milk protein addition to a carbohydrateelectrolyte solution resulted in better water retention than the carbohydrate-electrolyte solution when the energy density,

Table 1. Components of experimental drinks

\begin{tabular}{lccccc}
\hline & $\begin{array}{c}\text { Energy } \\
\text { density }(\mathrm{kJ} / \mathrm{l})\end{array}$ & $\begin{array}{c}\text { Lipid } \\
(\mathrm{g} / \mathrm{l})\end{array}$ & $\begin{array}{c}\text { Osmolality } \\
(\mathrm{mOsm} / \mathrm{l})\end{array}$ & $\begin{array}{c}\mathrm{Na}^{+} \\
(\mathrm{mmol} / \mathrm{l})\end{array}$ & $\begin{array}{c}\mathrm{K}^{+} \\
(\mathrm{mmol} / \mathrm{l})\end{array}$ \\
\hline Water & 0 & 0 & 19 & 0.6 & 0 \\
Milk & 2856 & 39 & 255 & 18.6 & 38.3 \\
$\begin{array}{l}\text { Sports } \\
\quad \text { drink }\end{array}$ & 1130 & 0 & 340 & 19.5 & 5.0 \\
MPS & 631 & 0 & 32 & 1.6 & 3.3 \\
MES & 2856 & 0 & 141 & 21.7 & 38.3 \\
\hline
\end{tabular}

MPS, milk protein solution; MES, milk electrolyte solution. fat content, $\mathrm{Na}$ and $\mathrm{K}$ concentration were matched between the experimental drinks.

These previous studies clearly demonstrated the body fluid retention effect of milk protein but it was unclear whether the milk protein additively enhances the body fluid retention by the $\mathrm{Na}$ solution or the milk protein itself exerts the body fluid retention. These previous studies also did not elucidate the mechanisms by which protein in rehydration drinks favours total body fluid retention. One of the proposed mechanisms suggests that the rate of gastric emptying is slower for milk than for water ${ }^{(13)}$. However, the effect of milk protein itself on gastric emptying has not been investigated to date. Moreover, changes of plasma vasoactive hormones following milk protein solution have not been investigated during rehydration after exercise.

In this study, we investigated gastric emptying rates and changes in plasma composition after administration of a milk protein solution (MPS) that was free of electrolyte. Because an electrolyte in milk affects water retention ${ }^{(14)}$, we estimated the effects of MPS prepared by dialysis. To evaluate the effect of removing milk protein from milk, we also obtained a milk electrolyte solution (MES) by preparing a eu-energetic electrolyte and dextrin solution.

This study comprised three experiments to investigate the effect of milk protein on body fluid retention. In the first experiment, total body fluid retention and changes in the composition of urine were studied in a dehydrated rat model. In the second experiment, the gastric emptying rate of MPS was estimated using a stable isotope marker. In the third experiment, plasma $\mathrm{Na}, \mathrm{K}$ and aldosterone levels were measured.

\section{Experimental methods}

Animals

Male 8-week-old Wistar rats $(200$ - 250 g; Specific PathogenFree (SPF); Japan Shizuoka Laboratory Center) were individually housed in cages $(33 \times 23 \times 23 \mathrm{~cm})$ under controlled conditions of temperature $\left(24.5 \pm 1^{\circ} \mathrm{C}\right)$, humidity $(55 \pm 5 \%)$ and light ( $12 \mathrm{~h}$ light $-12 \mathrm{~h}$ dark cycle). Rats were provided with a stock diet (Charles River Formula (CRF-1); Oriental Yeats Co. Ltd) and water ad libitum. They were accustomed to treadmill running at a $0 \%$ gradient and a speed of $2.5 \mathrm{~m} / \mathrm{min}$ for the first $10 \mathrm{~min}$ and $8.5 \mathrm{~m} / \mathrm{min}$ for the last $10 \mathrm{~min}$ (KN-73, Natsume Seisakusho Co. Ltd) two times during 1 week of the acclimatisation period. All procedures were performed in accordance with the Animal Experimentation Guidelines of Sugiyama Jogakuen University.

\section{Experimental materials}

Milk (Meiji Co. Ltd), sports drink (Pocari Sweat; Otsuka Co. Ltd) and dextrin (Cyclic cluster dextrin; Esaki Glico Co. Ltd) were used. MPS was obtained by overnight dialysis of milk in Visking membrane tubes (Medical Science Co. Ltd). MES was prepared by mixing $\mathrm{KCl}, \mathrm{NaCl}$ and $\mathrm{KH}_{2} \mathrm{PO}_{4}$ (Wako Pure Chemical Co. Ltd). The composition and 
osmolality of the experimental solutions are shown in Table 1. In Experiment 2, $\left[2-{ }^{13} \mathrm{C}\right]$ acetic acid was added to experimental drinks (Cambridge Isotope Laboratories Inc.) at a concentration of $0 \cdot 1 \mu \mathrm{l} / \mathrm{ml}$.

\section{Experimental design}

Experiment 1: urine volume and osmolality. A total of eighty-three rats were starved for $20 \mathrm{~h}$ from 17.00 hours and were deprived of fluids from 11.00 hours on the day of the experiment. They ran on a treadmill for $60 \mathrm{~min}(11.00$ to 12.00 hours) at a $0 \%$ gradient and a speed of $2.5 \mathrm{~m} / \mathrm{min}$ for the first $10 \mathrm{~min}$ and $8.5 \mathrm{~m} / \mathrm{min}$ for the last $50 \mathrm{~min}$. Rats were housed in custom-made metabolism cages for urine collection from 12.00 to 17.00 hours. Average body weight reduction from the baseline values was $3.1 \mathrm{~g}$ and body fluid loss was $1.2 \%$ of pre-exercise body weight. The experimental drinks water, milk, sports drink, MPS and MES were orally administered at the dose of $2.4 \%$ of baseline body weight (average $6.0 \mathrm{ml}$ ) using a stomach sonde under diethyl ether anaesthesia at 13.00 hours. After administration, urine was collected every $1 \mathrm{~h}$ for $4 \mathrm{~h}$ and was stored below $-20^{\circ} \mathrm{C}$. Urine was collected and weighed, and osmolality and $\mathrm{Na}^{+}$and $\mathrm{K}^{+}$concentrations were measured.

Experiment 2: gastric emptying rate. A total of fifteen rats were treated as in Experiment 1 except that they were housed in a respiratory metabolic chamber to collect respiratory gas. The experimental drinks water, milk, MPS and sports drink contained $\left[2{ }^{13} \mathrm{C}\right]$ acetic acid at a dose of $0 \cdot 1 \mu \mathrm{l} / \mathrm{ml}$. Respiratory ${ }^{13} \mathrm{CO}_{2}$ analysis was performed using an open-circuit metabolic gas analysis system connected directly to a mass spectrometer (model ARCO2000; ArcoSystem). The gas analysis system has been described in detail elsewhere ${ }^{(15,16)}$. Room air was pumped through the chambers at a rate of $0.5 \mathrm{litres} / \mathrm{min}$. Expired air was dried in a thin cotton column and then directed to a

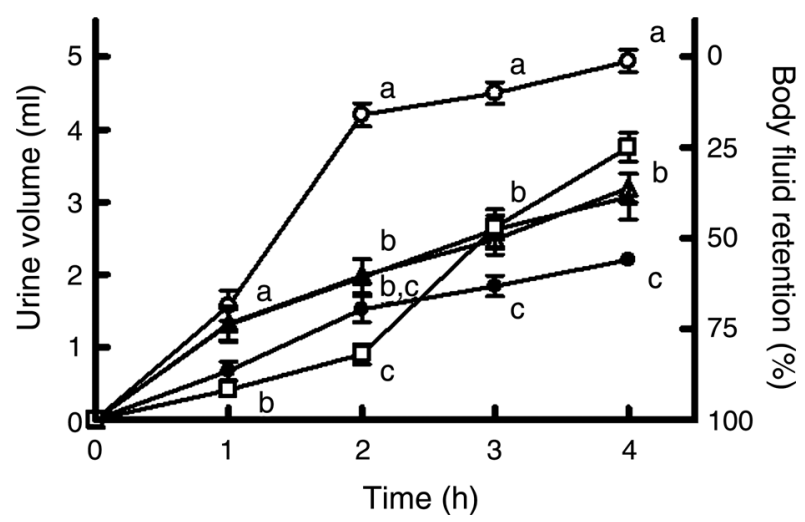

Fig. 1. Cumulative urine excretion over time after consumption of the five experimental drinks in Expt 1: water (-O-); milk (- -$)$; sports drink $\left(-\boldsymbol{\Delta}_{-}\right)$; milk protein solution (MPS; $-\boldsymbol{\Lambda}_{-}^{-}$); milk electrolyte solution (MES; $-\square^{-}$). The right $y$-axis indicates body fluid retention expressed as a percentage relative to the water group. Values are means, with standard errors represented by vertical bars $(n 13,14,18,19$ and 19 for water, milk, sports drink, MPS and MES, respectively). ${ }^{\mathrm{a}, \mathrm{b}, \mathrm{c}}$ Mean values with unlike letters were significantly different $(P<0.05)$.
MS $\mathrm{O}_{2} / \mathrm{CO}_{2}$ analyser. The peak time of ${ }^{13} \mathrm{CO}_{2}$ emission was used as the index of gastric emptying rate for each experimental drink ${ }^{(17)}$.

Experiment 3: blood collection and plasma osmolality. A total of sixty rats were treated as in Experiment 1 and administered the experimental drinks water, milk, MPS and sports drink. Blood was collected from the common iliac vein under ether anaesthesia at $30 \mathrm{~min}, 1 \mathrm{~h}$ and $2 \mathrm{~h}$ after the administration of drinks. Plasma was collected and osmolality and $\mathrm{Na}^{+}$and $\mathrm{K}^{+}$concentrations were measured.

\section{Sample analysis}

Osmolality of plasma and urine was measured cryoscopically using an osmometer (Osmomat 030; Gonotec). The concentrations of $\mathrm{Na}^{+}$and $\mathrm{K}^{+}$in plasma and urine were analysed using $\operatorname{HPLC}^{(18)}$. Briefly, plasma and urine were deproteinised and dried by centrifugation under vacuum. $\mathrm{Na}, \mathrm{K}, \mathrm{Mg}$ and $\mathrm{Ca}$ ions were separated in a mobile phase buffer $(0.75 \mathrm{~mm}-$ sulfuric acid, 0.25 mm-copper sulfate (II); $\mathrm{pH} 2.4$ ) on a super IC-cation column $(4.6 \mathrm{~mm}$ inner diameter $\times 150 \mathrm{~mm}$; Tosoh Co.), and ions were detected using an indirect UV method $(230 \mathrm{~nm})$. Plasma aldosterone levels were measured using an ELISA kit (Enzo Biochem Inc.).

\section{Statistics}

Values are expressed as means with their standard errors. The between-group comparisons of single-point measurements were made using one-way ANOVA followed by Tukey's post hoc test. The time course studies of urine osmolality and electrolyte excretion were compared using two-way ANOVA followed by Bonferroni post hoc tests. Significance was set at $P<$ 0.05. All statistical analyses were performed using Prism software (Windows version 4.03; GraphPad Software).

\section{Results}

\section{Urine volume (Experiment 1)}

The mean body mass loss during the dehydration protocol was $1.2 \%$ of the initial body weight. There were no differences in body mass loss between experimental groups. The volumes of urine excreted each hour over the course of the experiment $(4 \mathrm{~h})$ are presented in Fig. 1. Drinks ingested following exercise significantly altered cumulative volumes of urine excreted over the course of the 4-h recovery period $(P<0 \cdot 0001)$. Urine excretion was significantly less in the milk group compared with that in the water group $(P<0 \cdot 05)$. The volume of urine excreted by rats in sports drink, MPS and MES groups was more than that by rats in the water group and less than that by rats in the milk group. Additionally, the volume of urine collected by the MES group drastically increased $3 \mathrm{~h}$ after rehydration, although there were no significant changes in urine volume between MES- and milk-administered groups for the initial $2 \mathrm{~h}$ of rehydration. 
The cumulative volume of urine collected from milk, MPS and MES groups was 55, 31, and $23 \%$ less than that from the water group $4 \mathrm{~h}$ after rehydration, respectively. These percentages reflect the retention of body fluid during the 4-h recovery period (Fig. 1, right $y$-axis). Furthermore, the sum of body fluid retentions in the MPS (31\%) and MES (23\%) groups equalled that in the milk group $(55 \%)$. Thus, milk protein could contribute to $56 \%$ (i.e. $31 / 55 \%$ ) of the body fluid retention of milk. In preliminary studies comparing whole milk to fat-free milk (data not shown) and MES $(2866 \mathrm{~kJ} / \mathrm{l})$ to MES without dextrin $(0 \mathrm{~kJ} / \mathrm{l}$; data not shown), the energetic content of the drinks showed no significant effect on the volume of urine excreted.

\section{Urinary sodium and potassium excretion (Experiment 1)}

There was a significant difference in the urinary electrolyte concentrations after consumption of rehydration solution (Table 2). Rats in milk and MES groups, whose drinks contain more electrolyte than the other experimental drinks, showed significantly larger urinary $\mathrm{Na}$ and $\mathrm{K}$ excretion compared with that in the water and MPS groups at $2 \mathrm{~h}$ after rehydration $(P<0 \cdot 05)$. However, urinary $\mathrm{Na}$ excretion tended to be lower in rats administered milk compared with those administered MES $1 \mathrm{~h}$ after rehydration, whereas urinary $\mathrm{K}$ excretion was not significantly different between these groups.

\section{Urine osmolality (Experiment 1)}

Urine osmolality differed significantly depending on the drink administered $(P<0.05$; Fig. 2$)$. In the milk group, urine osmolality was significantly higher than that in the water group at 2 and $3 \mathrm{~h}$ after administration $(P<0 \cdot 05)$. In the MES group, urine osmolality was also significantly higher than that in the water group at $2 \mathrm{~h}(P<0 \cdot 05)$, but the difference disappeared at $3 \mathrm{~h}$ after rehydration. At $3 \mathrm{~h}$ of rehydration, urine osmolality in MPS-administered rats was less than that of the milk group and more than that of the water group.

\section{Gastric emptying rate (Experiment 2)}

Gastric emptying of milk was slightly slower than that for other experimental drinks, although this difference was NS. There were also no differences between gastric emptying times of MPS, water and the sports drink (Table 3).

\section{Plasma aldosterone (Experiment 3)}

In comparing the two electrolyte-free drinks (MPS and water), plasma aldosterone levels were significantly higher in the MPS group than in the water group. Despite the Na content of milk, plasma aldosterone levels in rats administered milk were higher than that those in rats administered water. Conversely, plasma aldosterone levels were slightly lower after rehydration with the sports drink than with water because $\mathrm{Na}$ lowers plasma aldosterone, although this difference was NS (Fig. 2).
Plasma osmolality and electrolyte concentration (Experiment 3)

Plasma Na concentration levels showed a significant decrease after administration of all the drinks. However, plasma $\mathrm{Na}$ level increased again after administration of milk or MPS, but not after the sports drink or water (Fig. 3(A)). Plasma K levels increased immediately after administration of all the drinks, but decreased to basal levels $3 \mathrm{~h}$ after the sports drink or water. In contrast, plasma $\mathrm{K}$ concentrations remained high in both the milk and MPS groups (Fig. 3(B)).

From 30 min to $2 \mathrm{~h}$ after administration, plasma osmolality in rats administered water and the sports drink decreased significantly compared with that in rats administered milk and MPS $(P<0 \cdot 05)$. At $4 \mathrm{~h}$ after administration, plasma osmolality in the MPS group was maintained at the initial level, while a decrease in plasma osmolality was observed in the other three groups, but was much slower in the milk group than that in the sports drink or water groups (Fig. 4).

\section{Discussion}

Rehydration after exercise is associated with smooth water absorption and total body fluid retention. In several previous studies, total body fluid retention has been shown to be superior in milk compared with that in isotonic electrolyte drinks ${ }^{(1-13)}$. While milk is considered an effective postexercise rehydration drink, the effect of milk protein itself on total body fluid retention has not been estimated. Here, we showed that the cumulative volume of urine excreted following rehydration in rats with milk, MPS and MES was 55, 31 and $23 \%$ less, respectively, than that with water $4 \mathrm{~h}$ after rehydration (Fig. 1). The $32 \%$ difference (55-23\%) between milk and MES may reflect the effects of milk protein on total body fluid retention, as both of these experimental drinks have equal electrolyte content and energy density. This difference of $32 \%$ was nearly equal to the $31 \%$ relative retention of urine in the MPS group. Given that MPS contains milk proteins but not electrolytes, milk protein itself appears to contribute $56 \%(31 / 55 \%)$ of the body fluid retention effect of milk.

Interestingly, urine volume from MES-administered rats rapidly increased $3 \mathrm{~h}$ after rehydration, while it was not different from that from the milk group for the first $2 \mathrm{~h}$ of rehydration (Fig. 1). This discrepancy between MES and milk may be related to differences in the composition of these two experimental drinks, with the most typical candidate substance being milk protein. James et al. ${ }^{(13)}$ also showed differences in urine volume after $3 \mathrm{~h}$ of rehydration with energy- and electolyte-matched carbohydrate and carbohydrate-milk protein solutions. Together, these findings suggest that milk protein is more effective in fluid retention than carbohydrate, although carbohydrate also exerts a mild influence on body fluid retention ${ }^{(10)}$.

Although previous studies have indicated the effectiveness of milk protein on body fluid retention, the mechanisms behind this have not been determined ${ }^{(11-13)}$. These reports indicate that protein clotting in the stomach delays the gastric emptying of milk. The half-emptying time of milk was 
Table 2. Urinary electrolyte excretion and osmolality following rehydration (Expt 1)* (Mean values with their standard errors)

\begin{tabular}{|c|c|c|c|c|c|c|c|c|c|c|c|}
\hline & \multicolumn{8}{|c|}{ Time after rehydration (h) } & & & \\
\hline & \multicolumn{2}{|c|}{1} & \multicolumn{2}{|c|}{2} & \multicolumn{2}{|c|}{3} & \multicolumn{2}{|c|}{4} & \multicolumn{3}{|c|}{ ANOVA $(P)$} \\
\hline & Mean & SEM & Mean & SEM & Mean & SEM & Mean & SEM & Drink & Time & Drink $\times$ time \\
\hline \multicolumn{12}{|l|}{$\mathrm{Na}^{+}(\mathrm{mmol} / \mathrm{l})$} \\
\hline Water & $2 \cdot 0^{\mathrm{b}}$ & 0.5 & $1.5^{\mathrm{c}}$ & 0.4 & 3.9 & 0.6 & $15 \cdot 0$ & 3.4 & 0.0001 & 0.0001 & 0.5968 \\
\hline Milk & $7 \cdot 5^{\mathrm{a}, \mathrm{b}}$ & 1.2 & $20 \cdot 4^{\mathrm{a}, \mathrm{b}}$ & $6 \cdot 7$ & 20.5 & 2.9 & 29.0 & 3.5 & & & \\
\hline Sports drink & $4.5^{\mathrm{a}, \mathrm{b}}$ & 0.6 & $6 \cdot 9^{\mathrm{a}, \mathrm{b}, \mathrm{c}}$ & 1.6 & $11 \cdot 3$ & $2 \cdot 8$ & $20 \cdot 1$ & $3 \cdot 1$ & & & \\
\hline MPS & $8 \cdot 1^{a, b}$ & $5 \cdot 0$ & $5 \cdot 8^{\mathrm{c}}$ & $2 \cdot 1$ & $11 \cdot 8$ & 3.4 & $19 \cdot 7$ & 4.4 & & & \\
\hline MES & $17 \cdot 2^{\mathrm{a}}$ & 4.1 & $20 \cdot 3^{a}$ & 3.5 & $17 \cdot 3$ & $2 \cdot 2$ & $22 \cdot 8$ & 3.4 & & & \\
\hline \multicolumn{12}{|l|}{$\mathrm{K}^{+}(\mathrm{mmol} / \mathrm{l})$} \\
\hline Water & $20 \cdot 4^{\mathrm{b}}$ & 3.7 & $13 \cdot 1^{\mathrm{c}}$ & $5 \cdot 0$ & $29 \cdot 0^{\mathrm{b}}$ & $8 \cdot 8$ & 31.4 & 3.0 & 0.0001 & 0.0001 & 0.0001 \\
\hline Milk & $33 \cdot 5^{a, b}$ & $6 \cdot 8$ & $68 \cdot 3^{a}$ & $10 \cdot 7$ & $75 \cdot 6^{a}$ & $6 \cdot 2$ & $44 \cdot 2$ & $6 \cdot 3$ & & & \\
\hline Sports drink & $29 \cdot 4^{a, b}$ & $5 \cdot 2$ & $37.9^{a, b, c}$ & $6 \cdot 7$ & $39.1^{\mathrm{b}}$ & 6.5 & 24.8 & 3.6 & & & \\
\hline MPS & $28 \cdot 6^{a, b}$ & 3.0 & $28 \cdot 4^{\mathrm{c}}$ & 3.0 & $50 \cdot 5^{a, b}$ & 8.5 & 41.5 & $6 \cdot 8$ & & & \\
\hline MES & $43 \cdot 6^{\mathrm{a}}$ & 3.5 & $59 \cdot 1^{a, b}$ & $7 \cdot 3$ & $41 \cdot 1^{\mathrm{b}}$ & $3 \cdot 3$ & $26 \cdot 0$ & 3.0 & & & \\
\hline \multicolumn{12}{|c|}{ Osmolality (mOsm/kg) } \\
\hline Water & 264.4 & $50 \cdot 8$ & $87 \cdot 3$ & $7 \cdot 6$ & $230 \cdot 2$ & 83.8 & 805.9 & 79.3 & 0.4015 & 0.9527 & 0.9671 \\
\hline Milk & 621.9 & 143.3 & 875.0 & $158 \cdot 1$ & $917 \cdot 2$ & 88.4 & 661.0 & $96 \cdot 1$ & & & \\
\hline Sports drink & 311.4 & 49.2 & 354.3 & 86.4 & 429.4 & 109.9 & 357.1 & 59.3 & & & \\
\hline MPS & $406 \cdot 1$ & $82 \cdot 8$ & $420 \cdot 0$ & 101.4 & 539.1 & 85.6 & 724.2 & 123.7 & & & \\
\hline MES & 595.6 & $59 \cdot 2$ & $725 \cdot 8$ & $121 \cdot 7$ & $376 \cdot 3$ & $42 \cdot 3$ & 267.9 & 37.9 & & & \\
\hline
\end{tabular}

MPS, milk protein solution; MES, milk electrolyte solution.

a,b,c Mean values with unlike superscript letters were significantly different $(P<0.05)$.

${ }^{*} n 13,14,18,19$ and 19 for water, milk, sports drink, MPS and MES, respectively.

estimated to be $14 \%$ slower than that of the sports drink ${ }^{(11)}$. We showed that the gastric emptying rate of MPS is not different from that of water or the sports drink, while the gastric emptying rate of milk is $14 \%$ slower as described by a previous report earlier (Table 3). To estimate the gastric emptying rate, we used ${ }^{13} \mathrm{C}$-labelled acetic acid as a marker in a respiratory gas analysis system. Absorption and oxidation of acetic acid are rapid, and can be utilised as a marker of gastric emptying rate ${ }^{(19)}$. The gas analysis system used in this study was optimised for the small volume of respiratory gas emitted by rats, and was sufficiently accurate for the purpose of the study ${ }^{(15,16)}$. The results show that milk protein itself does not

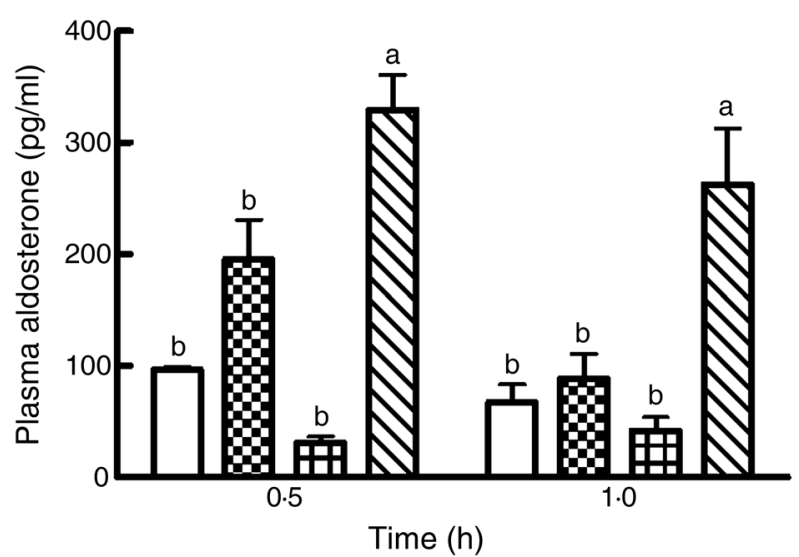

Fig. 2. Plasma aldosterone levels after consumption of the four experimental drinks in Expt 3: water ( $\square$ ); milk (8); sports drink (\#); milk protein solution (III). Values are means, with standard errors represented by vertical bars ( $n$ 15). a,b Mean values with unlike letters were significantly different $(P<0.05)$. lower the gastric emptying rate, and also indicates that this is slowed by interactions between protein and electrolyte fractions.

In a previous human study, urine osmolality $2 \mathrm{~h}$ after milk intake was about three to nine times higher than that following intake of water and a sports drink ${ }^{(11,13)}$. The same applied to the observation in the present study. Urine osmolality after administration of milk was maintained at a higher level than that after administration of the sports drink or water (Table 2). Given that the elevation of urine osmolality was greater than that of $\mathrm{Na}, \mathrm{K}$ or $\mathrm{Cl}$, another plasma component derived from milk may contribute to this elevated osmolality. Urinary $\mathrm{Na}$ excretion in the MES group was higher than that in the milk group during the first $1 \mathrm{~h}$ of rehydration. On the other hand, differences in urinary $\mathrm{K}$ excretion between rats administered MES and milk were not observed during the first hour of rehydration, but were significantly different at 3 and $4 \mathrm{~h}$ of rehydration (Table 2).

We have demonstrated that raised plasma aldosterone contributes to the total body fluid retention $30 \mathrm{~min}$ and $1 \mathrm{~h}$ after administration of milk (Fig. 2). However, as Na ingestion suppresses plasma aldosterone levels ${ }^{(20)}$, the difference between the milk and water groups was NS. The renin-angiotensinaldosterone system is, from an evolutionary viewpoint, a wellpreserved regulatory system with many morphological and physiological similarities in all vertebrate groups from fish to mammals ${ }^{(21)}$. The renin-angiotensin-aldosterone system is concerned with training-induced plasma volume expansion ${ }^{(22)}$. Elevation of plasma aldosterone level causes the reduction of renal $\mathrm{Na}$ excretion and the increasing of renal $\mathrm{Na}$ retention ${ }^{(23)}$. Thus the elevation of plasma aldosterone level positively affects body fluid retention. Aldosterone secretion is known to be regulated by various factors such as the 
(A)

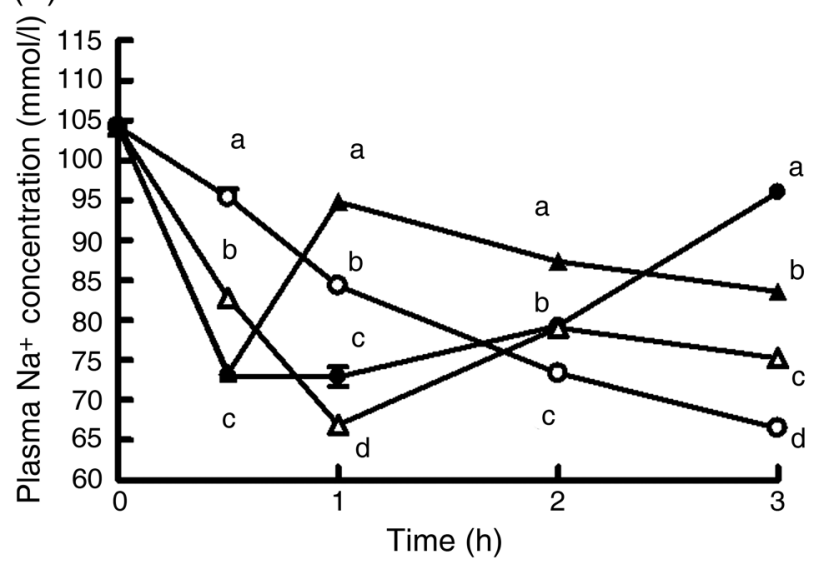

(B)

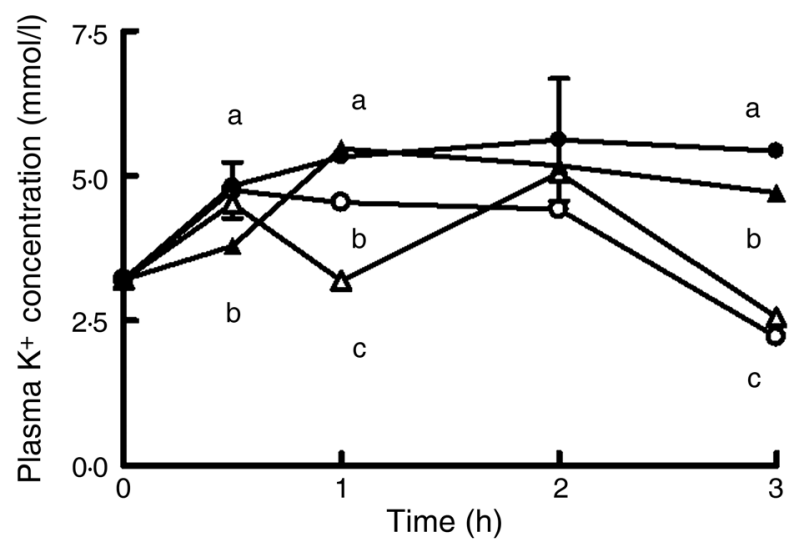

Fig. 3. Plasma sodium (A) and potassium (B) levels after consumption of the four experimental drinks in Expt 3: water (-O-); milk (-O-); sports drink $(-\boldsymbol{\Delta}-)$; milk protein solution $(-\boldsymbol{\Delta}-)$. Values are means, with standard errors represented by vertical bars $(n 15)$. ${ }^{a, b, c, d}$ Mean values with unlike letters were significantly different $(P<0.05)$.

renin-angiotensin system, adrenocorticotropic hormone and serum $\mathrm{K}$ concentration. We observed a significant reduction of plasma K (Fig. 3(B)) and a significant elevation of plasma aldosterone (Fig. 2) in the MPS group compared with the water group $30 \mathrm{~min}$ after administration. Although the

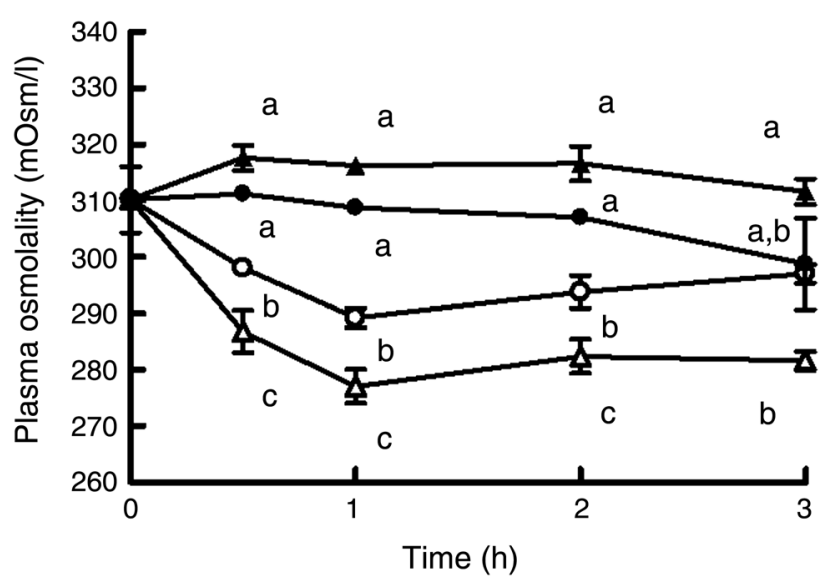

Fig. 4. Plasma osmolality after consumption of the four experimental drinks in Expt 3: water (-O-); milk (-O-); sports drink $\left(-\Delta^{-}\right)$; milk protein solution $(-\boldsymbol{\Delta}-)$. Values are means, with standard errors represented by vertical bars (n 5). ${ }^{\text {a,b,c }}$ Mean values with unlike letters were significantly different $(P<0.05)$.
Table 3. Gastric emptying rate of experimental drinks (Expt 2) ${ }^{\star}$ (Mean values with their standard errors)

\begin{tabular}{lcr}
\hline & \multicolumn{2}{c}{ Gastric emptying rate $(\min ) \dagger$} \\
\cline { 2 - 3 } & Mean & SEM \\
\hline Water & 54 & 5 \\
Milk & 62 & 1 \\
Sports drink & 50 & 7 \\
MPS & 52 & 9 \\
\hline
\end{tabular}

MPS, milk protein solution.

${ }^{*} n 4,3,4$, and 4 for water, milk, sports drink and MPS, respectively. $\dagger$ No significant differences were observed.

mechanism that induces aldosterone secretion is unclear, a 5-d high-protein diet ( $2 \mathrm{~g} / \mathrm{kg}$ body weight/d) caused increased plasma renin, aldosterone and vasopressin levels in human subjects ${ }^{(24)}$. Similar changes in vasoactive hormones may have occurred in the present study, as animals were orally administered approximately $1 \mathrm{~g} / \mathrm{kg}$ body weight at a time after exercise.

Elevation of plasma aldosterone positively affects body fluid retention by conserving plasma $\mathrm{Na}^{(20)}$. We showed that plasma aldosterone and Na levels in the MPS group were higher than in rats administered water or the sports drink $1-3 \mathrm{~h}$ after administration of the drink (Fig. 3(A), $P<0 \cdot 05$ ). In contrast to the MPS group, plasma $\mathrm{Na}$ levels in the water group decreased linearly for $3 \mathrm{~h}$ after administration. At this time point plasma $\mathrm{Na}$ levels were highest in the milk group, followed by the MPS group, the sports drink group and the water group. These data correlated with the total body fluid retention.

A decrease in plasma osmolality causes urination. In the present study, plasma osmolality in the MPS group was maintained at a higher level than that in the water and sports drink groups for $2 \mathrm{~h}$ after rehydration (Fig. 4). As MPS contained no electrolytes, this elevated plasma osmolality and $\mathrm{Na}$ retention cannot be explained by the electrolyte content of the drink. Therefore, higher plasma osmolality in the MPS group can be partially explained by the higher Na retention (Fig. 3(A)) and by other plasma components derived from milk, such as amino acids or their metabolites.

Most previous studies on body fluid retention have been conducted in human subjects by measuring the changes in body weight ${ }^{(2-11)}$. Although animal studies have several limitations in predicting the effect of milk protein solution on body fluid retention for human subjects, in this study, total body fluid retention was assessed using small laboratory animals. Of interest is whether there is a specific component in milk that affects body fluid retention. Given that it is difficult to obtain a large amount of effective fractions, experimental models using small laboratory animals are useful in evaluating the effects of small amounts of effective fractions on fluid retention. As precise urine collection is difficult in the small laboratory animal, we developed a protocol to measure fluid retention in rats, which requires precise measurement of urine volumes to avoid the confounding effect of body weight on volumes of faeces and urine. In conventional urine collection cages (metabolism cage), the separation of urine and faeces achieves a urine recovery rate of $64 \%$. To improve this, we 
developed a metabolism cage that recovers $93 \%$ of urine. Furthermore, dehydration was $1.2 \%$ of the body weight in rats.

The authors consider that the effects of anaesthesia on the experimental results were negligible. Inhalational anaesthetics influence renal function by reducing cardiac output and systemic blood pressure, and affecting the concentration of aldosterone, angiotensin II, atrial natriuretic peptide and vasopressin levels ${ }^{(25)}$. By means of anaesthesia by ether for $30 \mathrm{~min}$, urine volume was reported to decrease by half in a human study ${ }^{(26)}$. On the other hand, in the present study, as anaesthesia was performed for rapid oral administration, the aspiration of ether was within $2 \mathrm{~min}$. Therefore the influence of ether anaesthesia on the observation in the present study was negligible.

In summary, milk protein was responsible for $56 \%$ of the body fluid retention after milk consumption. Milk protein caused elevated plasma aldosterone levels and suppressed the reduction of plasma osmolality without delaying gastric emptying time. These data show that milk proteins maintain plasma osmolality and suppress body fluid loss.

\section{Acknowledgements}

This work was supported through Grants-in-Aid for Scientific Research (KAKENHI) by the Ministry of Education, Culture, Sports, Science and Technology of Japan (21700770 and 23700931). The authors acknowledge Ms Kei Inagaki, Ms Haruka Ishii, Ms Saori Suzuki and Ms Yoshie Murakami from Sugiyama Jogakuen University, and $\mathrm{Mr}$ Shigenobu Matsumura, Ms Aki Shoji and Ms Kayo Mizuno from Kyoto University for their expertise in the treatment of laboratory animals. All authors approved the submission of the manuscript and contributed as follows. K. I. conducted the experimental design and statistical analysis and wrote the manuscript; Y. K., A. U., M. Y. and A. Y. carried out experiments and proofread the manuscript; T. F. guided the analysis of respiratory gas and proofread the manuscript; and Y. S. conducted the experimental design and proofread the manuscript. All authors read and approved the final manuscript. There is no conflict of interest associated with the present study. The authors declare that there are no conflicts of interest.

\section{References}

1. Broad EM, Burke LM, Cox GR, et al. (1996) Body weight changes and voluntary fluid intakes during training and competition sessions in team sports. Int J Sport Nutr 6, 307-320.

2. Noakes TD (1993) Fluid replacement during exercise. Exerc Sport Sci Rev 21, 297-330.

3. Murray R \& Stofan J (2001) Formulating carbohydrate-electrolyte drinks for optimal efficacy. In Sports Drinks, pp. 183-196 [RJ Maughan and R Murray, editors]. New York: CRC.

4. Shirreffs SM, Taylor AJ, Leiper JB, et al. (1996) Post-exercise rehydration in man: effects of volume consumed and drink sodium content. Med Sci Sports Exerc 28, 1260-1271.
5. Maughan RJ, Leiper JB \& Shirreffs SM (1997) Factors influencing the restoration of fluid and electrolyte balance after exercise in the heat. Br J Sports Med 31, 175-182.

6. Maughan RJ \& Leiper JB (1995) Sodium intake and post-exercise rehydration in man. Eur J Appl Physiol Occup Physiol 71, 311-319.

7. Frisoli TM, Schmieder RE, Grodzicki T, et al. (2012) Salt and hypertension: is salt dietary reduction worth the effort? $A m \mathrm{~J}$ Med 125, 433-439.

8. Nielsen B, Sjogaard G, Ugelvig J, et al. (1986) Fluid balance in exercise dehydration and rehydration with different glucose-electrolyte drinks. Eur J Appl Physiol Occup Physiol 55, 318-325.

9. Shirreffs SM, Aragon Vargas LF, Keil M, et al. (2007) Rehydration after exercise in the heat: a comparison of 4 commonly used drinks. Int J Sport Nutr Exerc Metab 17, 244-258.

10. Osterberg KL, Pallardy SE, Johnson RJ, et al. (2010) Carbohydrate exerts a mild influence on fluid retention following exercise-induced dehydration. J Appl Physiol 108, 245-250.

11. Shirreffs SM, Watson P \& Maughan RJ (2007) Milk as an effective post-exercise rehydration drink. Br J Nutr 98, 173-180.

12. Watson P, Love TD, Maughan RJ, et al. (2008) A comparison of the effects of milk and a carbohydrate-electrolyte drink on the restoration of fluid balance and exercise capacity in a hot, humid environment. Eur J Appl Physiol 104, 633-642.

13. James LJ, Clayton D \& Evans GH (2011) Effect of milk protein addition to a carbohydrate-electrolyte rehydration solution ingested after exercise in the heat. Br J Nutr 105, 393-399.

14. Stachenfeld NS (2008) Acute effects of sodium ingestion on thirst and cardiovascular function. Curr Sports Med Rep 7, S7-S13.

15. Ishihara K, Oyaizu S, Fukuchi Y, et al. (2003) A soybean peptide isolate diet promotes postprandial carbohydrate oxidation and energy expenditure in type II diabetic mice. J Nutr 133, $752-757$.

16. Ishihara K, Oyaizu S, Mizunoya W, et al. (2002) Use of ${ }^{13}$ C-labeled glucose for measuring exogenous glucose oxidation in mice. Biosci Biotechnol Biochem 66, 426-429.

17. Uchida M, Endo N \& Shimizu K (2005) Simple and noninvasive breath test using ${ }^{13} \mathrm{C}$-acetic acid to evaluate gastric emptying in conscious rats and its validation by metoclopramide. J Pharmacol Sci $\mathbf{9 8}$, 388-395.

18. Yanai R, Sumida K \& Fujii T (2006) Simultaneous determination of sodium, potassium, magnesium and calcium ions in milk and other common drinks by high-performance liquid chromatography. Kawasaki Med Welfare J 16, 101-107.

19. Maughan RJ \& Leiper JB (1996) Methods for the assessment of gastric emptying in humans: an overview. Diabet Med 13, S6-S10.

20. Williams JS \& Williams GH (2003) 50th anniversary of aldosterone. J Clin Endocrinol Metab 88, 2364-2372.

21. Platzack B (1995) Blood pressure control by the renin-angiotensin system and its interaction with the sympathetic nervous system in fish. Braz J Med Biol Res 28, 1227-1231.

22. Costill DL, Branam G, Fink W, et al. (1976) Exercise induced sodium conservation: changes in plasma renin and aldosterone. Med Sci Sports 8, 209-213.

23. Convertino VA, Luetkemeier MJ, Elliott JJ, et al. (2000) Renal responsiveness to aldosterone during exposure to simulated microgravity. J Appl Physiol 89, 1737-1743.

24. Daniels BS \& Hostetter TH (1990) Effects of dietary protein intake on vasoactive hormones. Am J Physiol 258, R1095-R1100.

25. Burchardi H \& Kaczmarczyk G (1994) The effect of anaesthesia on renal function. Eur J Anaesthesiol 11, 163-168.

26. Kimura K (1969) Effect of ether anesthesia and surgery on plasma diuretic hormone $(\mathrm{ADH})$ levels in man. Masui 18, 10581070. 